\section{Growing Degree-day Requirements for Scheduling Flowering of Scadoxus multiflorus subsp. katharinae (Baker) Friis \& Nordal}

\author{
Keith A. Funnell ${ }^{1}$ \\ Institute of Natural Resources, Massey University, Private Bag 11-222, \\ Palmerston North, New Zealand
}

Additional index words. Haemanthus, blood lily, base temperature, heat sums, heat units, thermal time, anthesis

\begin{abstract}
Containerized plants of Scadoxus multiflorus subsp. katharinae (Baker) Friis \& Nordal were forced to anthesis under three environments of contrasting temperature. Flowering performance, growing degree-days (GDD) requirements for timing of anthesis, and the influence of cold storage $\left(12{ }^{\circ} \mathrm{C}\right.$ for 4 weeks) before forcing were evaluated. Total forcing time from the beginning of the experiment until anthesis decreased with warmer forcing environment, ranging between 129 and 86 days. Across all forcing environments, use of GDD was readily able to explain differences in time to anthesis resulting from both cold storage and forcing. Using a base temperature of $5{ }^{\circ} \mathrm{C}$, GDD requirements between beginning of the experiment and anthesis was $1166 \pm 124$ GDD, emergence of the vegetative shoot and anthesis $1075 \pm 118 \mathrm{GDD}$, and appearance of the tips of the leaf lamina and anthesis $883 \pm 91$ GDD. Using a base temperature of $11.5^{\circ} \mathrm{C}$, GDD requirements between appearance of tip of the involucre and anthesis was $180 \pm 44$ GDD, and the whole involucre being visible and anthesis $144 \pm 42$ GDD. In the next year, validation of the GDD requirements was achieved by subsequently forcing a second population of plants to anthesis for a specific date.
\end{abstract}

Scadoxus multiflorus subsp. katharinae (Baker) Friis \& Nordal is a selection from one of 60 species originating from riverine habitats in Natal, South Africa (Rees and Runger, 1985). Plants comprise shoots with between two and five leaves, the swollen bases of which form semiterrestrial rhizomatous rootstocks. Within a growing season, foliage typically emerges before any flowers. When flowering, the scape emerges from within the leaf bases of the previous season's growth but exterior to the current season's foliage. Once fully developed, the scape presents itself above the foliage canopy, comprising up to 100 or more individual flowers colored in orange-red tones.

In recent years, $S$. multiflorus subsp. katharinae has been viewed as a potential new landscape plant to be marketed when in flower. To fulfill this use, predictable production is required. Hence, producers are interested in understanding the flowering requirements of this species and developing production schedules. In other crop species, a common method of production scheduling uses the accumulation of heat units or sum

\footnotetext{
Received for publication 9 July 2007. Accepted for publication 31 Aug. 2007.

Funding for this research was in part provided by a TechNet grant by Technology NZ.

I thank Gardenza Ltd. for providing plant material and the staff at the Plant Growth Unit, Massey University, for maintaining the controlled environment facilities used in this study.

${ }^{1}$ To whom reprint requests should be addressed; e-mailk.funnell@massey.ac.nz.
}

of growing degree-days (GDD) to estimate the expected time to anthesis (Huang et al., 1999; Whitman et al., 1997).

Production scheduling of some herbaceous perennials must also account for their response to cold temperature. Some species require a period of cold temperature for flowering for either vernalization or breaking of bud dormancy (Iversen and Weiler, 1994; Whitman et al., 1996). The flowering response of $S$. multiflorus subsp. katharinae to cold temperatures has received scant reporting in the literature. A period of cold (optimally 10 to $15^{\circ} \mathrm{C}$ between 80 and 120 d) has been reported as optimal to break dormancy before forcing plants to flower (Peters, 1974).

The objectives of this experiment were to determine the GDD requirement for the various stages of development to anthesis and the influence of cold temperature before forcing on this.

\section{Materials and Methods}

Growing degree-day model development. Containerized plants of $S$. multiflorus subsp. katharinae were delivered to Massey University (Palmerston North, New Zealand; $40^{\circ} 20^{\prime} \mathrm{S}$ ) on 5 Sept. 2002. The 63 plants each comprised a grade size of between three and six shoots in 6.4-L containers. In the previous growing season, the plants had been grown in a semiprotected shade house near Pukekohe, New Zealand $\left(36^{\circ} 38^{\prime} \mathrm{S}\right)$ and had not been divided or repotted for at least 12 months. On arrival, the previous season's foliage had not yet begun to senesce.
Foliage from the previous season's growth was cut back on 11 Sept. and plants immediately allocated to treatment environments. Foliage was cut back to leave 3 to $5 \mathrm{~mm}$ of leaf bases above the surface of the growing medium. Before further treatment, 30 plants were placed directly at $12 \pm 2{ }^{\circ} \mathrm{C}$ within dark, cool storage for 4 weeks. Additionally, three plants were taken for dissection so as to determine the stage of floral development of each of the shoots per plant. The remaining 30 plants, and those once removed from cold storage, were randomly allocated to each of the three forcing treatment environments identified as: cool (shade house with no temperature control), warm (greenhouse heated at $15{ }^{\circ} \mathrm{C}, 20^{\circ} \mathrm{C}$ ventilation), and hot (greenhouse heated at $20^{\circ} \mathrm{C}, 25$ ${ }^{\circ} \mathrm{C}$ ventilation). Over the duration of forcing, average daily air temperatures within each of the forcing treatment environments followed the natural progression of spring and progressively increased (Fig. 1). Hence, within the forcing environment identified as "cool," daily average air temperatures progressed from 10 to $18{ }^{\circ} \mathrm{C}$, in the environment labeled "warm" from 16 to $21^{\circ} \mathrm{C}$, and in that labeled "hot" from 18 to $22{ }^{\circ} \mathrm{C}$. Additionally, each forcing treatment environment was provided with a spectrally neutral woven polypropylene shadecloth of nominal 30\% density. Photoperiod was not controlled and throughout the period of forcing ranged between 11:41 $\mathrm{h}$ and 15:03 $\mathrm{h}$.

The experiment comprised a factorial arrangement of three forcing environments and two durations of cold storage. Each forcing treatment comprised 20 individual plant replicates with 10 of these replicates additionally exposed to 4 weeks cold storage. Throughout the period of cold storage and forcing, growth was monitored three times per week and, for flowering shoots, the dates of attainment of five phenological stages of development were noted, i.e., a) emergence of next season's vegetative shoot between leaf bases of previous season's, b) emergence of leaf lamina, c) tip of involucre visible, d) whole involucre visible, and e) first floret open, i.e., anthesis (Fig. 2).

Within each forcing treatment environment, air temperature was monitored using either three or four shaded thermistors positioned at foliage height and recorded at 10min intervals $\left(\mathrm{T}_{10 \mathrm{~min}}\right)$ using a Squirrel 1200 Digital Meter/Logger (Grant Instruments Ltd., Barrington, Cambridge, UK). Encompassing both the period of cold storage and forcing, accumulated GDD from the date of the start of treatments ( $t$; i.e., 11 Sept. 2002) until attainment of each of the phenological stages of development ( $a$; Fig. 2) through to (e) were calculated using Eq. [1]:

$\mathrm{GDD}=\sum_{t}^{(a)-(e)}\left[\frac{\mathrm{T}_{10 \mathrm{~min}}-\mathrm{T}_{\mathrm{BASE}}}{\mathrm{n}_{10 \min }}\right]$ Eq. [1]

where $\mathrm{n}_{10 \text { min }}$ is the number of temperature recordings per day and if $\mathrm{T}_{10 \mathrm{~min}}$ less than $\mathrm{T}_{\text {BASE}}$, then $\mathrm{T}_{10 \mathrm{~min}}=\mathrm{T}_{\text {BASE}}$. 


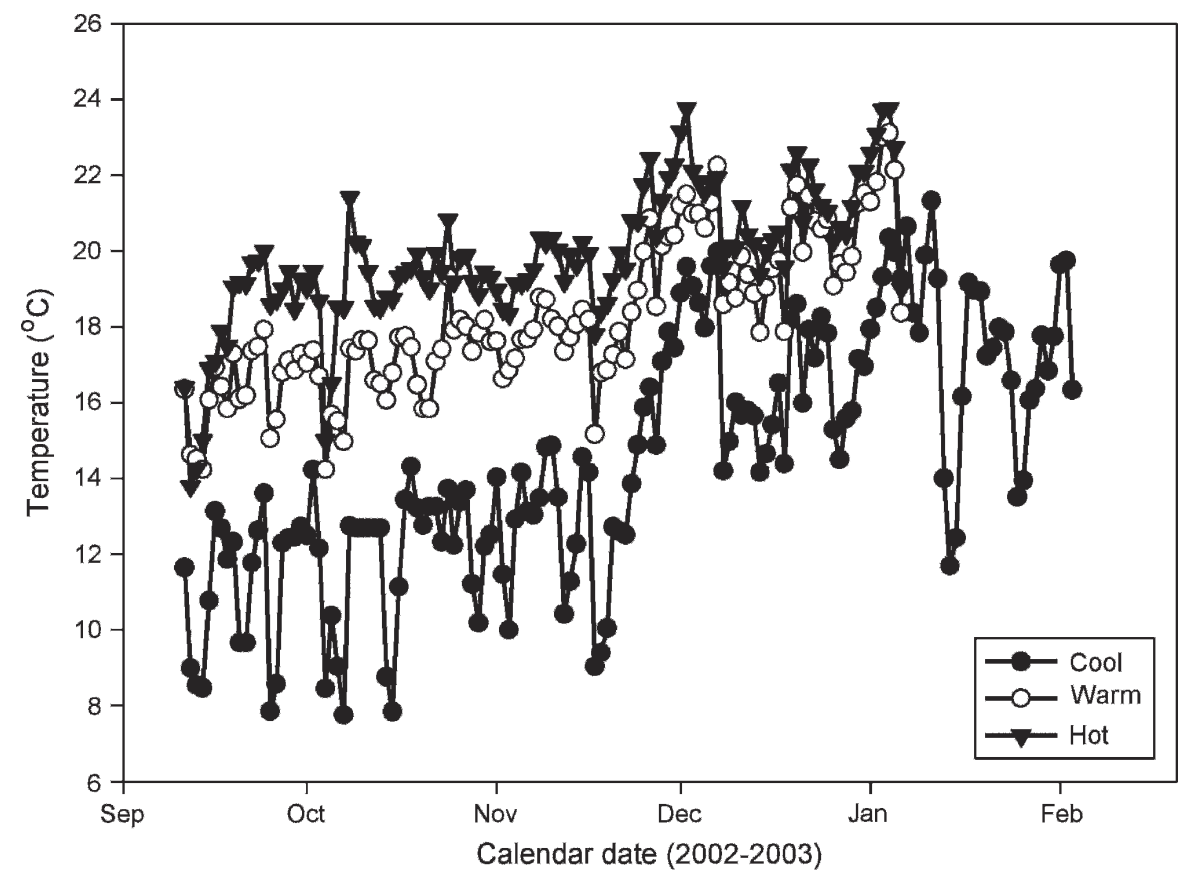

Fig. 1. Daily average air temperatures within each of three forcing environments during the first experiment. Each point is the average of 144 recordings at 10-min intervals for each of three or four sensors during a $24-\mathrm{h}$ period.

GDD between the start of the experiment $(t)$ and stage $(e),(a)$ and $(e),(b)$ and $(e),(c)$ and $(e),(d)$ and $(e)$ as well as calendar days between $(t)$ and $(e)$ were analyzed using a generalized linear routine (PROC GLM) within the Statistical Analysis System (SAS Institute, Cary, NC). For each interval between $(t)$ and the phenological stages of development $(a)$ through to $(e)$, the base temperature $\left(\mathrm{T}_{\mathrm{BASE}}\right)$ was determined by that which minimized the coefficient of variation of GDD calculated (Arnold, 1959).

Model validation. From the preceding experiment, the GDD estimate for attaining stage (e) was subsequently used to target $50 \%$ of the population reaching anthesis for a specific calendar date (21 Nov. 2003) in time for display at the Ellerslie Flower Show (25 to 30 Nov. 2003). Forty-five containerized plants of $S$. multiflorus subsp. katharinae were prepared as before and placed in a shaded $(30 \%)$ greenhouse heated at $15{ }^{\circ} \mathrm{C}$ and vented at $22^{\circ} \mathrm{C}$. Assuming a daily average temperature of $18.5{ }^{\circ} \mathrm{C}$ and a base temperature of $5{ }^{\circ} \mathrm{C}$ (refer to "Results and Discussion" subseqently), the estimated duration of forcing was $86 \mathrm{~d}$, implying a date of beginning the forcing treatment of 27 Aug. Throughout the period of forcing, growth was monitored three times per week and, for flowering shoots, the dates of attainment of the same five stages of development were noted (Fig. 2). Photoperiod was not controlled and throughout the period of forcing ranged between 10:59 $\mathrm{h}$ and 14:33 $\mathrm{h}$.

Air temperature within the greenhouse was monitored at 10 -min intervals as previously stated. Accumulated GDD from the date of the start of forcing ( $t$; i.e., 27 Aug. 2003) until attainment of each of the pheno-
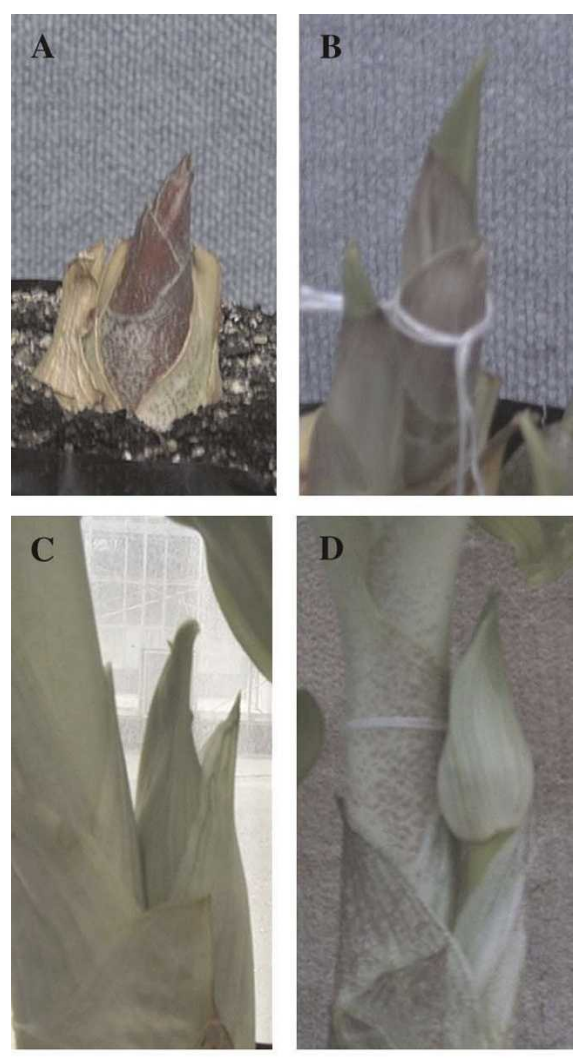

logical stages of development ( $a$; Fig. 2) through to $(e)$ were calculated using Eq. [1] with base temperatures as determined in the previous experiment.

GDD between the start of the experiment $(t)$ and stage $(e),(a)$ and $(e),(b)$ and $(e),(c)$ and $(e),(d)$ and $(e)$ as well as calendar days between $(t)$ and $(e)$ were analyzed using a generalized linear routine (PROC GLM) within the Statistical Analysis System (SAS Institute).

\section{Results and Discussion}

Growing degree-day model development. Only one shoot per plant was found to contain differentiated floral primordia when dissected at the start of treatment application. When present, floral shoots emerged from a rhizome comprised of either seven or nine swollen leaf bases from the previous season's growth. The emerging shoot comprised either three or four protective cataphylls with a single prophyll subtending the inflorescence from its axillary position on the primary stem axis. Above the point of attachment of the inflorescence, the primary axis comprised eight differentiated leaf primordia, five nondifferentiated primordia, and the apical meristem. All flower parts were fully differentiated within each of the flowers making up an inflorescence; hence, floral initiation was complete by the beginning of the experiment.

Within each treatment, at least one inflorescence per plant reached anthesis, and only four plants within the entire experiment developed more than one inflorescence. No influence of cold storage or forcing treatment environment on floral productivity was noted. Hence, low inflorescence numbers per

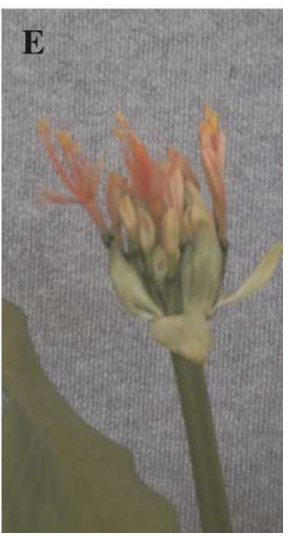

Fig. 2. Phenological stages of development for flowering shoots of S. multiflorus subsp. katharinae: (A) emergence of next season's vegetative shoot between leaf bases of previous season's, (B) emergence of leaf lamina; (C) tip of involucre visible; (D) whole involucre visible; (E) first floret open, i.e., anthesis.

plant does not appear to result from the cold storage and forcing environments used in this study. This interpretation is consistent with results reported by Peters (1974) in which only prolonged exposure to temperature extremes of $5{ }^{\circ} \mathrm{C}$ or less or $25^{\circ} \mathrm{C}$ or greater reduced floral productivity. If a greater number of inflorescence per plant is desired, determining what controls development leading to floral initiation would be more likely to result in a potential improve-

Total forcing duration until anthesis decreased with incrementally warmer forcing environment from $129 \pm 8 \mathrm{~d}$ under the cool environment to $91 \pm 7 \mathrm{~d}$ under the warm and $86 \pm 8 \mathrm{~d}$ under the hot environment ment in this parameter. 
$(P<0.001)$. There was an interaction between forcing environment and the duration of cold storage with total forcing time being reduced by $3 \mathrm{~d}$ after 4 weeks of storage when forced under the cool regime and extended by up to $8 \mathrm{~d}$ when forced under the warm and hot regimes $(P<0.05$; Fig. 3$)$. However, in contrast to the findings reported by Peters (1974), there was no influence of cold storage on duration to anthesis that could not be explained by GDD alone (Fig. 3). Visible emergence of shoots (Fig. 2A) began during cold storage at $12{ }^{\circ} \mathrm{C}$, and air temperatures in the cool forcing environment were frequently below $12{ }^{\circ} \mathrm{C}$ from September through the end of November (Fig. 1). With growth evident during cold storage, the reduced duration to anthesis compared with those in the cooler forcing environment, and longer duration compared with those continuously in the warm and hot forcing environments, is understandable.

The plants used in the current experiment were likely to have already received 4 months at temperatures considered optimal for breaking dormancy (Peters, 1974). Hence, the absence of any additional dormancybreaking response to exposure to cold storage is also understandable. Peters (1974) noted that once dormancy had been completely satisfied, plants reached anthesis between 83 and $89 \mathrm{~d}$ at $25{ }^{\circ} \mathrm{C}$. This is not dissimilar to the $86 \pm 8 \mathrm{~d}$ encountered in the current experiment under the hot $\left(18\right.$ to $\left.22{ }^{\circ} \mathrm{C}\right)$ forcing environment. Hence, this provides further evidence that in the current experiment, dormancy had most likely been satisfied before treatments began.

For early stages of development $(t, a$, and $b$ ) through to anthesis (stage $e$ ), the base temperature that minimized the coefficient of variation ranged between 4 and $6{ }^{\circ} \mathrm{C}$ (Fig. 4A). When continuously exposed to temperatures of $5{ }^{\circ} \mathrm{C}$ or less for $55 \mathrm{~d}$ or longer, Peters (1974) reported damage to plants of 'Konig Albert', a hybrid between S. multiflorus subsp. katharinae (Baker) Friis \& Nordal and Scadoxus puniceus (L.) Friis \& Nordal. Hence, for a plant species originating in a warm-temperate climate (Friis and Nordal, 1976), a base temperature between 4 and $6{ }^{\circ} \mathrm{C}$ for periods that encompass these early stages of development is not surprising.

For later stages of development ( $c$ and $d$ ) through to anthesis (stage $e$ ), the base temperature was 11 and $12^{\circ} \mathrm{C}$, respectively (Fig. $4 \mathrm{~B})$. For other crop species, the base temperature increased by as much as $6.3^{\circ} \mathrm{C}$ with later stages of development (Angus et al., 1981; Porter et al., 1987); hence, a similar change in the current study is not unexpected.

Across all cold storage and forcing treatments, anthesis (stage $e$ ) was attained after $1166 \pm 124$ GDD $\left(\mathrm{T}_{\mathrm{BASE}}=5{ }^{\circ} \mathrm{C}\right)$ from the start of the experiment (stage $t$; Fig. 3). In other crops, when any dormancy requirement has been satisfied, differences in timing has been explained by including GDD accumulated during the period of cold storage (Huang et al., 1999). In the current experiment, with growth evident during cold

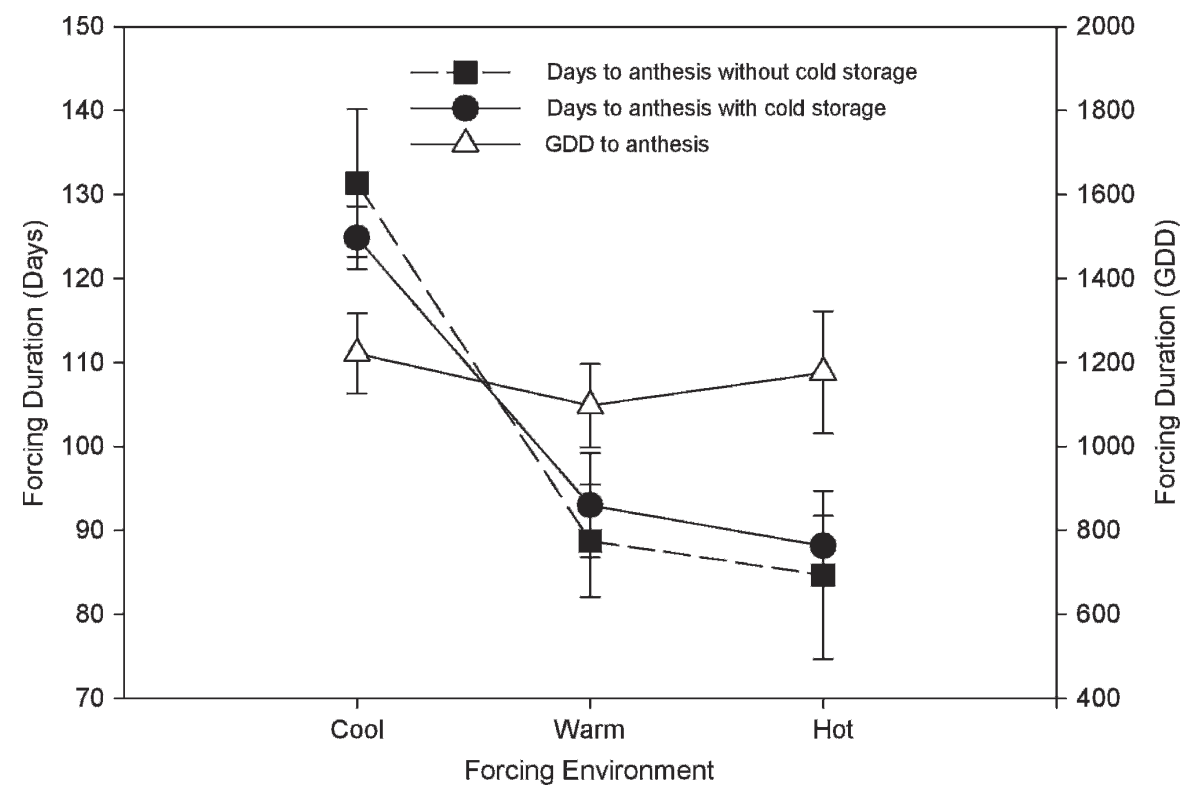

Fig. 3. Total forcing duration in either calendar days or growing degree-days (GDD) from the beginning of the experiment $(t)$ until anthesis $(e)$ for plants of $S$. multiflorus subsp. katharinae forced under one of three environments with or without cold storage. Base temperature for GDD was $5{ }^{\circ} \mathrm{C}$. For days to anthesis, $\mathrm{n}=10$; for GDD $\mathrm{n}=20$. Vertical lines $=2 \mathrm{x}$ SD.
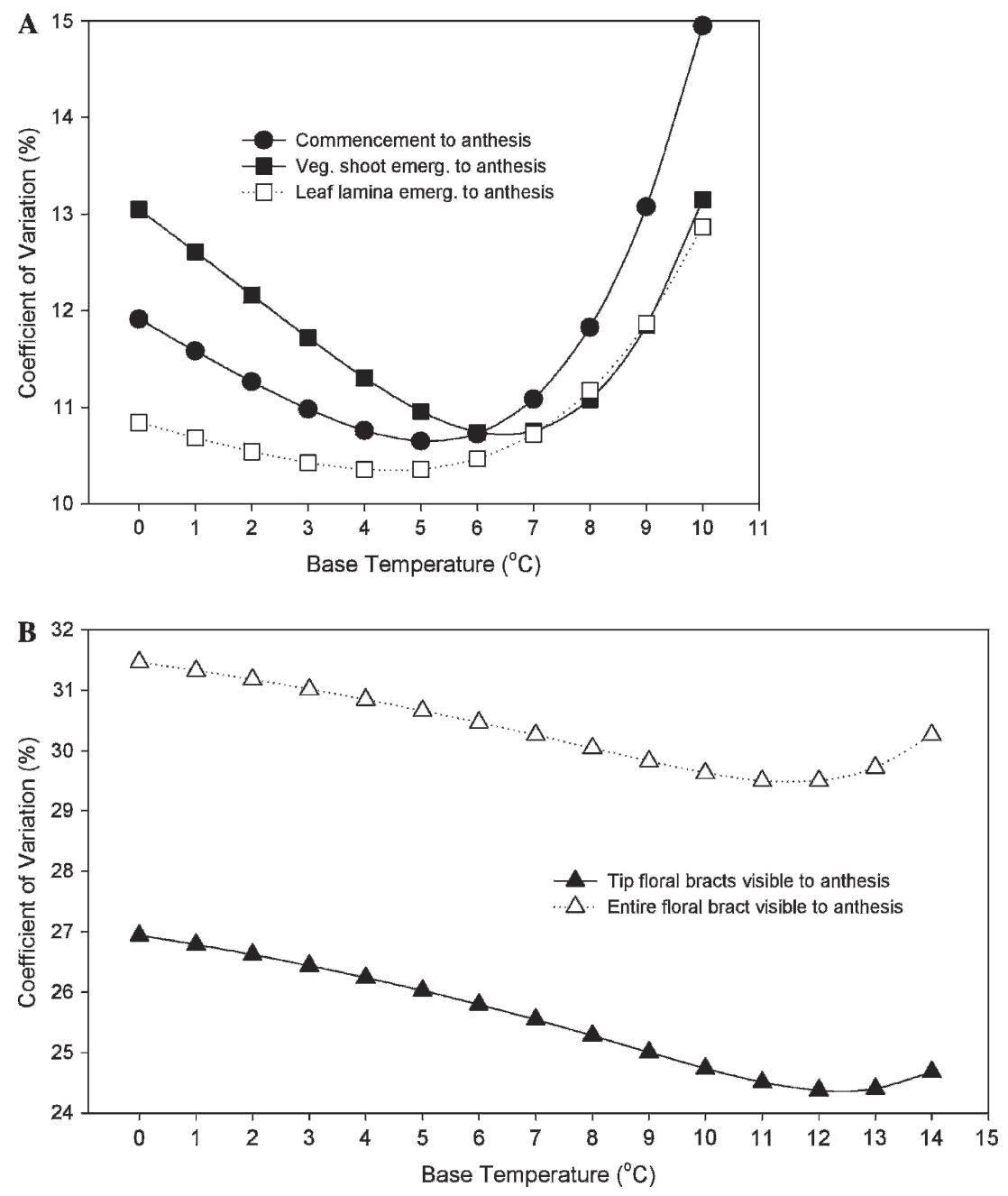

Fig. 4. Coefficient of variation of forcing duration [growing degree-days (GDD)] until anthesis (stage $e$ ) with changing base temperature for plants of $S$. multiflorus subsp. katharinae during forcing from (A) start of the experiment $(t)$, vegetative shoot emergence (stage $a$ ), and emergence of leaf lamina tips (stage $b$ ); (B) tip of involucre visible (stage $c$ ) and whole involucre visible (stage $d$ ). $\mathrm{n}=60$. 
storage and any dormancy likely to have already been satisfied, including the period of cold storage within the calculation of GDD, similarly explained the differences in timing between treatments.

Between emergence of the vegetative shoot (stage $a$ ) and anthesis, $1075 \pm 118$ GDD $\left(\mathrm{T}_{\mathrm{BASE}}=5^{\circ} \mathrm{C}\right)$ were accumulated and $883 \pm 91$ GDD between the appearance of the tips of the leaf lamina (stage $b$ ) and anthesis.

Across all cold storage and forcing treatments, anthesis (stage $e$ ) was attained after $180 \pm 44 \mathrm{GDD}\left(\mathrm{T}_{\mathrm{BASE}}=11.5^{\circ} \mathrm{C}\right)$ from the appearance of the tip of the involucre (stage $c$ ) and $144 \pm 42$ GDD between when the whole involucre was visible (stage $d$ ) and anthesis.

Model validation. All 45 plants produced an inflorescence reaching anthesis $80 \pm 8 \mathrm{~d}$ after the start of forcing. This mean duration to anthesis was within the bounds of variation from the $86 \mathrm{~d}$ estimated after the first experiment and enabled 38 plants to be shipped on the targeted date of 21 Nov. Although being within the variation established in the first experiment, the mean value of $80 \mathrm{~d}$ was, nonetheless, $6 \mathrm{~d}$ earlier than estimated before the start of the validation experiment. Actual air temperatures during forcing averaged $19.5^{\circ} \mathrm{C}$ compared with the $18.5^{\circ} \mathrm{C}$ assumed in the estimation calculations. As a result, when converted to GDD, the difference between actual and predicted dates were taken into account with a total of $1172 \pm 124$ GDD $\left(\mathrm{T}_{\mathrm{BASE}}=5{ }^{\circ} \mathrm{C}\right)$ accumulated for plants to reach anthesis from the start of forcing. This value of GDD was within the bounds of the $1166 \pm 124$ established in the first experiment and equated to a difference of less than $1 \mathrm{~d}$ 's growing time at temperatures encountered in either the first or second experiment.

Progression of stages of development $(a)$ and $(b)$ through to $(e)$ occurred after $1073 \pm$
120 and $882 \pm 95$ GDD $\left(\mathrm{T}_{\mathrm{BASE}}=5^{\circ} \mathrm{C}\right)$ were accumulated, respectively. Stages of development $(c)$ and $(d)$ through to $(e)$ occurred after $180 \pm 45$ and $144 \pm 41$ GDD $\left(\mathrm{T}_{\mathrm{BASE}}=\right.$ $11.5{ }^{\circ} \mathrm{C}$ ) were accumulated, respectively. Each of these values was within the bounds of variation established in the first experiment.

Validation of the GDD model was conducted under similar seasonal conditions of light used in the first experiment. Although based on experiments using Scadoxus multiflorus (Martyn) Raf., Vendrame et al. (2004) indicated a possible hastening of development to anthesis with increased daily light integral or photoperiod. Hence, to provide a scheduling model that is robust for application under other light regimes, examination of the need to include these environmental parameters is required.

Using environments with daily average air temperatures ranging between 10 and $22{ }^{\circ} \mathrm{C}$, a schedule for predictable flowering of plants of $S$. multiflorus subsp. katharinae can now be constructed to meet predicted market demand. Although higher and lower air temperatures may also be satisfactory to enable scheduled forcing, the full range of the linear temperature response for this crop remains to be clarified. In constructing a schedule, as long as plants had their dormancy requirement satisfied, no additional cold storage was required.

\section{Literature Cited}

Angus, J.F., D.H. MacKenzie, R. Morton, and C.A. Schafer. 1981. Phasic development in field crops II. Thermal and photoperiodic responses of spring wheat. Field Crops Res. 4:269-283.

Arnold, C.Y. 1959. The determination and significance of the base temperature in a linear heat units system. Proc. Amer. Soc. Hort. Sci. 74: 430-445.

Friis, I.B. and I. Nordal. 1976. Studies on the genus Haemanthus (Amaryllidaceae) IV. Division of the genus into Haemanthus s. str. and Scadoxus with notes on Haemanthus s. str. Norway J. Bot. 23:63-77.

Huang, N., K.A. Funnell, and B.R. MacKay. 1999. Vernalization and growing degree-day requirements of Thalictrum delavayi 'Hewitt's Double'. HortScience 34:59-61.

Iversen, R. and T. Weiler. 1994. Strategies to force flowering of six herbaceous garden perennials. HortTechnology 4:62-65.

Peters, J. 1974. Influence of temperature on the vegetative and generative development of Haemanthus $\times$ hybridus cv. 'Konig Albert'. Scientia Hort. 2:357-368.

Porter, J.R., E.J.M. Kirby, W. Day, J.S. Adam, M. Appleyard, S. Ayling, C.K. Baker, P. Beale, R.K. Belford, P.V. Biscoe, A. Chapman, M.P. Fuller, J. Hampson, R.K.M. Hay, M.N. Hough, S. Matthews, W.J. Thompson, A.H. Weir, V.B.A. Willington, and D.W. Wood. 1987. An analysis of morphological development stages in Avalon winter wheat crops with different sowing dates and at ten sites in England and Scotland. J. Agr. Sci. 109:107-121.

Rees, A.R. and W. Runger. 1985. Haemanthus, p. 304-305. In: A.H. Halevy (ed.). CRC handbook of flowering. Vol I. CRC Press, Boca Raton, FL.

Vendrame, W.A., J. Garofalo, and A.W. Meerow. 2004. Effects of light duration on flower development in blood lily. Proc. Fla. State Hort. Soc. 117:341-345.

Whitman, C.M., R.D. Heins, A.C. Cameron, and W.H. Carlson. 1996. Cold treatments, photoperiod, and forcing temperature influence flowering of Lavandula angustifolia. HortScience 31:1150-1153.

Whitman, C.M., R.D. Heins, A.C. Cameron, and W.H. Carlson. 1997. Cold treatment and forcing temperature influence flowering of Campanula carpatica 'Blue Clips'. HortScience 32:861-865. 